\title{
PENGGUNAAN APLIKASI GPR (GROUND PENETRATING RADAR) DENGAN METODE NON-DESTRUCTIVE UNTUK KOLEKTIFITAS DATA KUALITATIF PADA ANALISA SUBSURFACE TANAH EKSTRIM LUNAK
}

\author{
Alam Tronics, S.Si, MT. ${ }^{1)}$ dan Ivan Bahder, S.Si, MTA. ${ }^{1)}$ \\ ${ }^{1)}$ Departemen Geologi, PT. Kaltim Prima Coal
}

\begin{abstract}
ABSTRAK
Ground-Penetrating Radar (GPR) adalah metode Geofisika dengan menggunakan teknologi radar untuk identifikasi perlapisan batuan dan "subsurface" pada investigasi geoteknik. Metode ini termasuk metode "non-destructive" (tanpa melakukan perusakan pada original base) menggunakan gelombang elektromagnetik dengan panjang gelombang mikro (Frekuensi UHF/VHF) yaitu pada garis spektrum gelombang radio dan dapat mendeteksi signal reflektif dari struktur bawah tanah. Kedalaman kemampuan alat GPR untuk "sensing" (penetrasi pembacaan) pada struktur batuan/tanah dengan GPR mencapai ketebalan 50m. GPR bisa mendeteksi (sensing) perubahan arah perlapisan batuan dan memprediksi ketebalan tanah ekstrim lunak, sehingga dapat mengidentifikasi resiko dan menekan biaya penanganan (reduction impact cost) dari perilaku extreme base sebelum proses "dumping" di area berawa atau gambut. Penggunaan instrumen GPR juga dapat menunjang detail interpretasi pengeboran geologi PT. KPC. Metode ini digunakan sebagai metode alternatif jika metode pengeboran geologi terlalu berbahaya dilakukan karena lereng yang diinvestigasi berada pada kondisi kritis atau area rawa yang tidak bisa dilalui mobilisasi rig drilling. Geoteknik KPC telah melakukan investigasi geoteknik dengan alat GPR yang telah dikorelasikan dengan data CPT. Pada korelasi nilai konstanta dielektrik dengan nilai CPT, dengan rentang 56.09 sampai 61.08 memiliki nilai konus terkoreksi, qt dengan rentang 0.12 MPa sampai 0.21 MPa. Hasil akhirnya akan diperoleh persamaan empiris data GPR vs data CPT.
\end{abstract}

Kata kunci: investigasi geoteknik, non-destructive, sensing, dan reduction impact cost

\begin{abstract}
Ground-Penetrating Radar (GPR) is Geophysical Method by using Radar Technology to purpose identification rock bedding and subsurface on geotechnical investigation. This method is classified for non-destructive application (without doing damage the original base) and applied by Electromagnetic Wave with microwave bandwidth (Frequency UHF/VHF) in spectrographic transmitting-wave (radio wave) and also to detect reflective pulse from the ground. Performance modulation depth of the GPR for sensing (beam penetration) rock/soil is for 50m. The GPR can detect (sensing) changes in the direction of rock bedding and for predicting extremely soft soil thickness, so as to identify risks and reduce handling cost (reduction impact cost) from extreme base behavior before the dumping process in marshy or peat areas. The use of GPR instruments can also support detailed interpretation of geological drilling in PT. KPC.This method is used as an alternative method if the geological drilling method is too dangerous to act, because the slopes investigated are in critical condition or swampy areas that cannot be traversed by drilling rig mobilization. KPC geotechnics have conducted geotechnical investigations with GPR tools that have been correlated with data CPT. The result of the correlation of dielectric constant values with $C P T$ values, with a range of 56.09 to 61.08 has a corrected cone value, $q_{t}$ with a range of 0.12 MPa to $0.21 \mathrm{MPa}$. The final result is empirical correlation between data GPR and data CPT.
\end{abstract}

Keynote: geotechnical investigation, non-destructive, sensing, and reduction impact cost 


\section{A. PENDAHULUAN}

Berdasarkan peta geologi regional yang ditunjukkan pada Gambar 1 untuk wilayah Sangatta di tahun 1995 menunjukkan pengembangan pembuangan limbah yang diusulkan dalam Formasi Balikpapan (Tmbp) dan Alluvium (Qal). Formasi Balikpapan (Tmbp) terdiri dari pasir, tanah liat, lanau, tufa, dan batu bara dalam perubahan batu pasir kuarsa, tanah liat, lanau yang terjadi sebagai lapisan dasar dan laminasi paralel. Alluvium (Qal) diindikasikan sebagai tanah liat dan lanau, pasir dan kerikil, dari endapan pantai dan sungai.

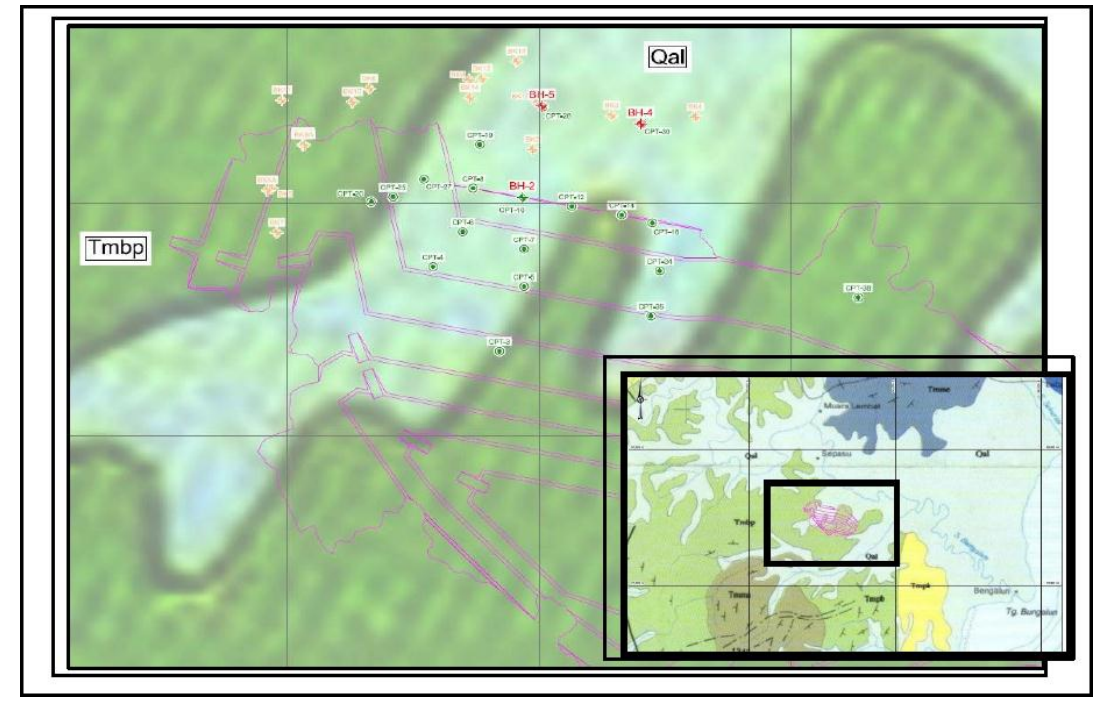

Gambar 1. Peta Geologi Lokasi Penelitian

Metode Ground Penetrating Radar (GPR) atau biasa disebut sebagai Georadar, terdiri dari dua kata, yaitu Geo yang berarti bumi dan Radar singkatan dari radio detection and ranging, sehingga dapat diartikan sebagai Radar sebagai alat pelacak bumi yang menggunakan panjang gelombang radio. GPR dapat diaplikasikan untuk eksplorasi dangkal (near surface) dengan ketelitian (resolusi) yang amat tinggi sehingga mampu mendeteksi benda di bawah permukaan bumi hingga dimensi beberapa puluhan meter (Arif, 2016).

$G P R$ merupakan metode Geofisika yang dapat digunakan untuk menyelidiki keadaan lereng dan metode ini tergolong non-destructive field soil investigation (tidak merusak) karena menggunakan sumber gelombang elektromagnetik. Metode ini digunakan sebagai alternatif apabila metode pengeboran terlalu berbahaya dilakukan pada lokasi tingkat kesulitan yang tidak bisa dijangkau atau kritis kestabilannya. Metode Ground Penetrating Radar memiliki keuntungan karena memiliki biaya operasionalnya yang rendah, prosedur pengerjaan mudah dan ketelitian tinggi (resolusi tinggi). Metode ini bekerja dengan memanfaatkan teknologi Radar yang memancarkan semacam gelombang elektromagnetik yang kemudian ditangkap balik oleh sensor alat (receiver). Spektrum frekuensi yang digunakan disesuaikan kebutuhan pengukurannya. Gelombang yang dipancarkan adalah gelombang pendek (microwave) agar mendapatkan prenetrasi ke bawah permukaan bumi. Respons data yang diterima akan diolah berdasarkan hukum pantulan (refleksi) dan pembiasan gelombang (Arif, 2016).

Sistem $G P R$ secara sederhana bertujuan untuk mengukur amplitude gelombang terhadap waktu rambat gelombang. Skema dari sistem GPR dapat ditunjukkan pada Gambar 2, 3 dan 4. Pada Gambar 2 adalah unit pengaturan waktu, yang mengontrol pembentukan dan deteksi sinyal. Sebagian besar GPR beroperasi dalam domain waktu. Namun, pengukuran pada domain frekuensi saat ini digunakan untuk merubah respons gelombang pada domain waktu. 
Pada penelitian ini dengan alat GPR dilakukan di wilayah KPC di area settling pond dengan kondisi di lapangan original rawa-rawa dan sebagian berupa tanah bekas rawa-rawa. Litologi daerah penelitian tersusun atas tanah lunak yaitu gambut, lanau lempungan dan pasir lempungan. Berdasarkan referensi penelitian J.A. Huisman dkk 2003 yang berjudul "Measuring Soil Water Content with Ground Penetrating Radar" menjelaskan untuk menghitung kandungan air dalam tanah dapat menggunakan metode Ground Penetrating Radar dengan akuisisi borehole Zero Offset Profiling dan Multi Offset Profilling yang dibandingkan dengan hasil pembacaan nilai Cone Penetrometer Test (Gambar 5). Selain itu, penelitian ini menggunakan metodologi penentuan kandungan air tanah dengan membandingkan kecepatan gelombang permukaan, kecepatan gelombang yang dikirimkan diantara borehole dan dari koefisien refleksi permukaan.

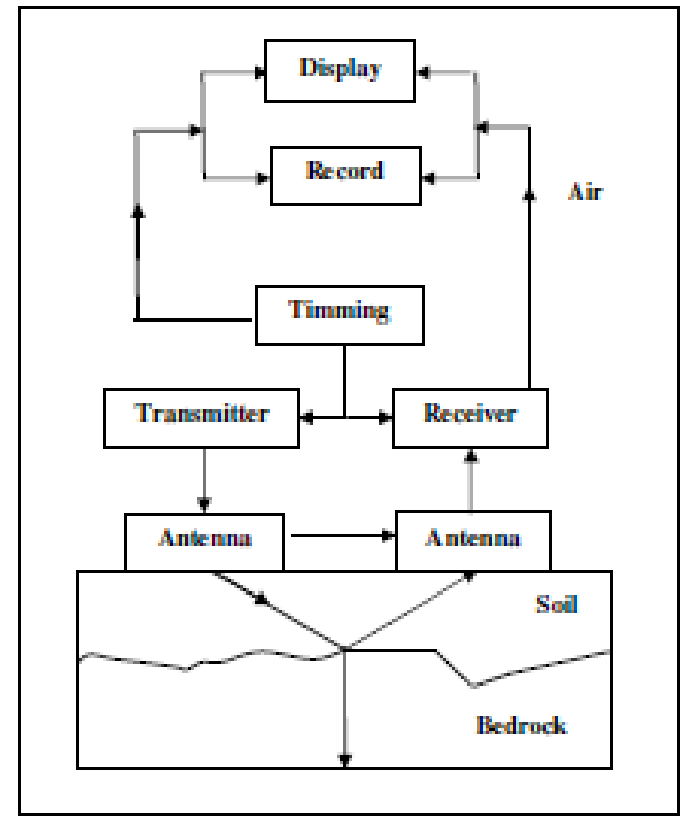

Gambar 2. Sistem Kerja Ground Penetrating Radar (Modifikasi Annan, 2003)

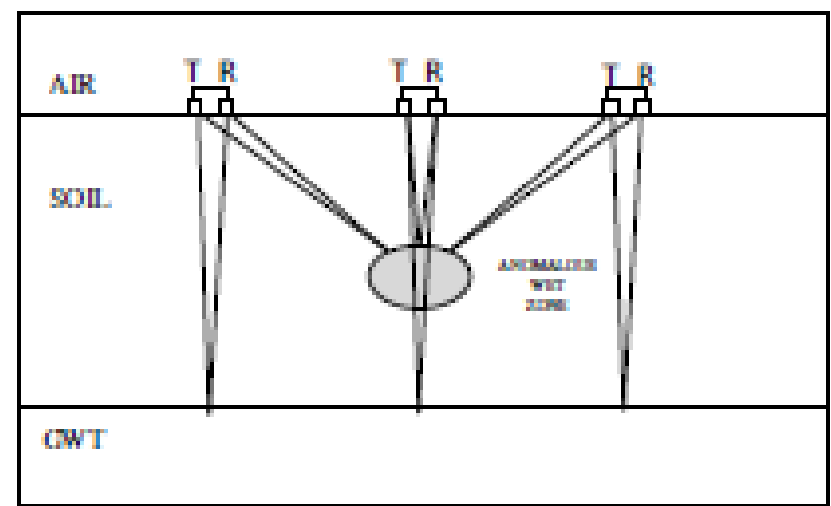

Gambar 3. Ilustrasi Penjalaran gelombang Ground Penetrating Radar (Annan, 1989) 


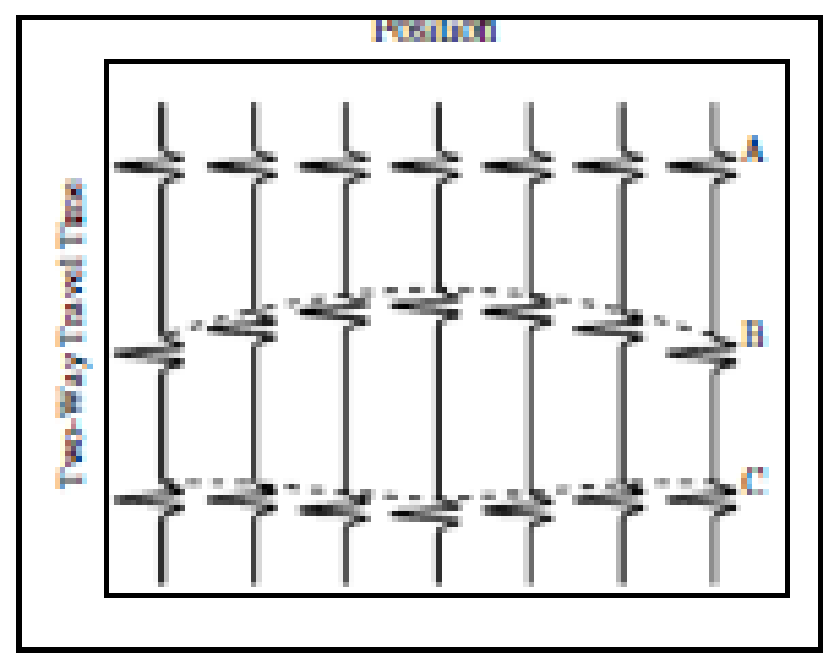

Gambar 4. Respon Penjalaran gelombang Ground Penetrating Radar (Annan, 1989)

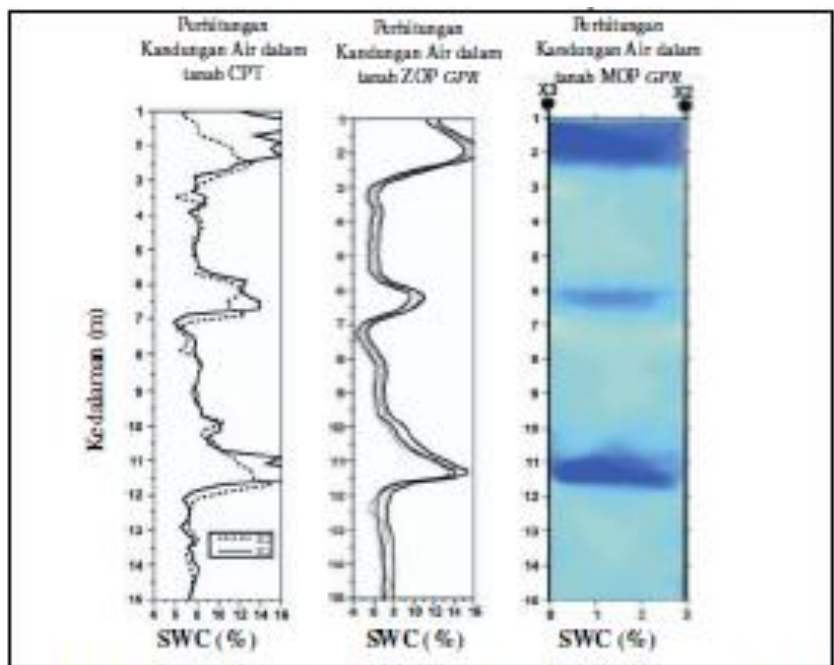

Gambar 5. Grafik Perhitungan Kandungan Air dalam Tanah Berdasarkan CPT, ZOP GPR dan MOP GPR.

Persamaan yang digunakan dalam penelitian tsd adalah persamaan Topp et al (1988) tentang hubungan nilai konstanta dielektrik dengan kandungan air dalam tanah yaitu :

Keterangan:

$$
\theta v=5.3 \times 10^{-2}+2.92 \times 10^{-2} \varepsilon-5.5 \times 10^{-4} \varepsilon^{2}+4.3 \times 10^{-6} \varepsilon^{3}
$$

$\varepsilon=$ Konstanta Dielektrik

$\theta_{\mathrm{v}}=$ Kandungan Air dalam Tanah

\section{B. METODOLOGI PENELITIAN}

Menurut Annan (2003) karakteristik sistem GPR memiliki tugas yang kompleks, sehingga perlu pengelolaan kekuatan sensitivitas sinyal pada operasional dan penggunaan sistem. Faktor-faktor instrumentasi elektronik yang mengatur karakterisasi GPR adalah pembangkitan sinyal, metode penangkapan sinyal, pemrosesan sinyal, faktor kinerja, rentang dinamis, frekuensi dan bandwidth, konsistensi, dan mudah dibawa. Antena mentransformasikan sinyal listrik ke dan dari medan vektor elektromagnetik. 


\section{B.1. Metode Kurk}

Metode perhitungan Kruk merupakan metode perhitungan kecepatan berdasarkan ketebalan lapisan. Metode ini merupakan metode perhitungan yang digunakan pada metode seismik refleksi dan digunakan dalam metode $G P R$. Metode perhitungan ini yaitu menggunakan rumus seperti yang terlihat pada Gambar 6.

Dengan menggunakan rumus Pythagoras maka didapatkan rumus:

Dapat dijabarkan :

$$
s^{2}=h^{2}+\left(\frac{x}{2}\right)^{2}
$$

$$
t^{2}=\frac{4 h^{2}+x^{2}}{v^{2}}
$$

Sehingga

$$
v=\sqrt{\frac{4 h^{2}+x^{2}}{t^{2}}}
$$

Setelah mendapatkan nilai kecepatan maka dapat dihitung nilai permitivitasnya dengan menggunakan persamaan:

$$
\varepsilon_{r}=\left(\frac{c}{v}\right)^{2}
$$

Keterangan :

$\mathrm{s}:$ Jarak pantul (m)

$\mathrm{h}:$ Kedalaman $(\mathrm{m})$

$\mathrm{x}: \operatorname{Offset}(\mathrm{m})$

$\mathrm{t}:$ Waktu (ns)

$v:$ Kecepatan rambat gelombang $(\mathrm{m} / \mathrm{ns})$

$\varepsilon_{r}:$ Konstanta dielektrik

c : Kecepatan cahaya $(0,3 \mathrm{~m} / \mathrm{ns})$

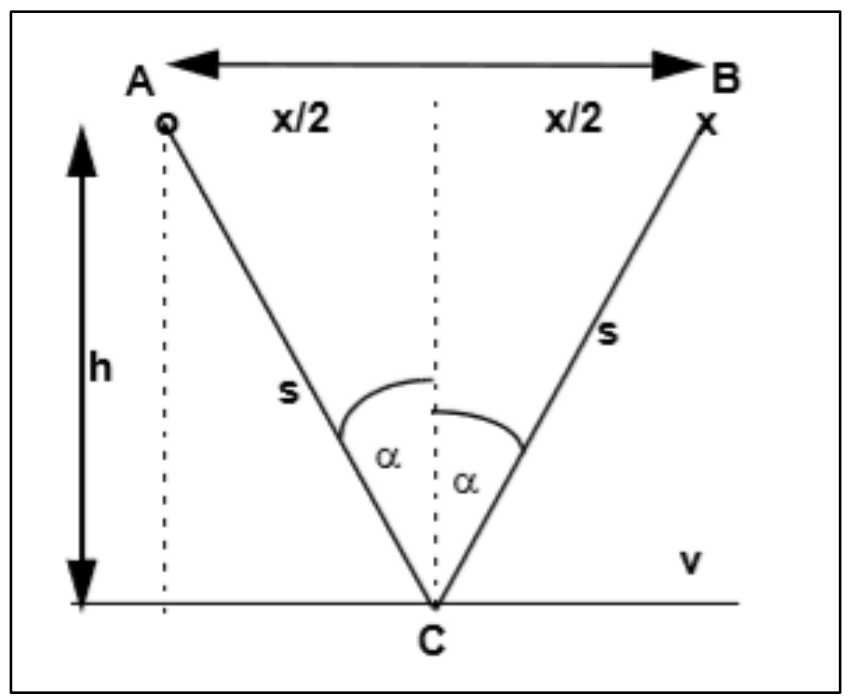

Gambar 6. Pemantulan Gelombang (Kruk, 2007)

\section{B.2. Konstanta Dielektrik}

Medium memiliki sifat dielektrik yang ditentukan oleh harga konstanta dielektrik, atau permitivitas dielektrik dari suatu medium tersebut. Permitivitas dielektrik suatu medium dalam sistem satuan Standard Internasional (S.I) skala besar mempergunakan satuan farad per meter (F/m). Pengertian fisis permitivitas dielektrik suatu medium menunjukkan ukuran kemampuan suatu medium atau suatu bahan untuk meredam intensitas medan listrik yang melalui medium itu. Permitivitas dielektrik relatif dinyatakan dalam simbol $\varepsilon_{r}$ yang menyatakan kemampuan medium untuk meredam intensitas medan listrik relatif terhadap ruang vakum, sehingga didefinisikan: 


$$
\varepsilon=\varepsilon_{o} \varepsilon_{r}
$$

Pada persamaan tersebut yaitu $\varepsilon_{o}$ adalah permitivitas dielektrik ruang vakum atau udara bebas, $\varepsilon_{r}$ adalah permitivitas relatif suatu medium tersebut. Suatu bahan yang tidak isotrop yaitu bahan yang memiliki sifat dielektrik yang berbeda untuk arah yang berbeda, misalnya memiliki koefisienkoefisien dielektrik relatif $\varepsilon_{r 1}$ yaitu permitivitas relatif medium pertama, $\varepsilon_{r 2}$ yaitu permitivitas medium kedua dan $\varepsilon_{r 3}$ yaitu permitivitas medium ketiga. Dua medium dielektrik dengan permitivitas relatif yang berbeda $\varepsilon_{r 1}$ dan $\varepsilon_{r 2}$ mempunyai hubungan lapis batas komponen-komponen normal dan tangensial dari vector intensitas medan listrik dan vektor rapat fluksnya. Sebagai contoh untuk vektor rapat fluks listrik $\mathrm{D}_{1}$ datang dari medium 1 dengan permitivitas dielektrik $\varepsilon_{r l}$ menuju ke medium 2 dengan permitivitas dielektrik relatif $\varepsilon_{r 2}$ dengan sudut datang $\theta_{1}$ dan sudut bias $\theta_{2}$ seperti pada gambar yang menjelaskan bahwa komponen normal vektor rapat fluks listrik dari medium 1 ke medium 2 tidak berubah oleh perubahan medium (Rustam dkk, 2007).

Tabel 1. Konstanta Dielektrik dan Kecepatan Gelombang Radio Pada Material Reynolds (1985, 1990b, 1991b, 2011) et all

\begin{tabular}{|c|c|c|}
\hline Material & $\boldsymbol{\varepsilon}_{\boldsymbol{r}}$ & $\mathbf{V}(\mathbf{m m} / \mathbf{n s})$ \\
\hline Udara & 1 & 300 \\
\hline Air & 81 & 33 \\
\hline Pasir (kering) & $3-6$ & $122-173$ \\
\hline Pasir (basah) & $10-32$ & $53-90$ \\
\hline Lanau (kering) & $7-21$ & $51-61$ \\
\hline Lanau (basah) & $24-34$ & 95 \\
\hline Lempung (kering) & $2-5$ & $134-212$ \\
\hline Lempung (basah) & $8-40$ & $47-106$ \\
\hline Gambut & $57-80$ & $33-40$ \\
\hline Tanah (rata - rata) & 16 & 75 \\
\hline Tanah (berbutir baik) & $41-49$ & $43-47$ \\
\hline Serpih (basah) & $6-9$ & $100-122$ \\
\hline Batubara & $4-5$ & $134-150$ \\
\hline
\end{tabular}

\section{B.3. Uji Sondir}

Sondir merupakan alat uji tahanan tanah untuk menguji daya dukung insitu dan kuat geser total per kedalaman yang diuji. Dalam pengoperasiannya bagian ujung sondir yang berbentuk kerucut (cone) disebut konus ditekan kedalam tanah dengan kecepatan $1 \mathrm{~cm}$ hingga $2 \mathrm{~cm}$ per detik (penetrasi) sejauh $5 \mathrm{~cm}$ dan nilai tahanan ujung $\left(q_{t}\right)$ dibaca melalui indikator tekanan yang disebut manometer dalam $\mathrm{kg} / \mathrm{cm}^{2}$. Kemudian ujung sondir ditekan sedalam $5 \mathrm{~cm}$ lebih jauh sehingga sisi kerucut ikut bergerak sehingga tahanan total $\left(\mathrm{q}_{1}\right)$ dari ujung dan selimut konus (sleeve skin) dapat dibaca pada penunjuk tekanan (manometer). Selanjutnya tahanan sisi $\left(q_{s}\right)$ dari selimut konus $\left(q_{t}\right)$ dapat dihitung dari selisih pembacaan tekanan total $\left(\mathrm{q}_{1}\right)$ dengan tahanan ujung $\left(q_{t}\right)$ :

$$
q_{s}=\left(q_{1}-q_{t}\right) \cdot f k
$$

dengan $f_{k}$ adalah faktor korelasi dari pembacaan penunjuk tahanan ujung menjadi tahanan sisi yang merupakan perbandingan dari luas penampang kerucut dibandingkan dengan luas selimut konus:

$$
\mathrm{f}_{\mathrm{k}}=\frac{\text { Luas penampang ujung konus }}{\text { Luas sisi selimut konus }}
$$

Luas penampang ujung konus pada umumnya sebesar $10 \mathrm{~cm}^{2}$, sedangkan luas sisi selimut bervariasi dari 110 hingga $150 \mathrm{~cm}^{2}$. Dengan memasukkan harga tersebut kedalam Persamaan (7), nilai faktor koreksi $\mathrm{f}_{\mathrm{k}}$ adalah 0.067 hingga 0.091 . Selanjutnya perbandingan antara nilai tahanan sisi $\left(\mathrm{q}_{\mathrm{s}}\right)$ dengan tahanan ujing $\left(q_{t}\right)$ dapat dihitung sebagai rasio friksi $\left(R_{f}\right)$. Nilai $R_{f}$ mempunyai arti yang sangat penting dalam memperkirakan jenis lapisan tanah secara empiris. Berdasarkan penelitian sebelumnya telah diketahui bahwa jenis tanah berbutir kasar (pasir) memiliki $R_{f}$ yang lebih kecil dibandingkan dengan tanah berbutir halus (lempung dan lanau). 
Penetrasi konus dan pembacaannya diulang-ulang tiap selang $20 \mathrm{~cm}$ hingga mencapai kedalaman tertentu tergantung keperluan (estimasi kedalaman \pm 30 meter). Pengujian dapat dihentikan setelah tahanan ujung konus menunjukkan angka $250 \mathrm{~kg} / \mathrm{cm}^{2}$. Hasil pengujian sondir memberikan data yang cukup dapat diandalkan untuk keperluan analisis lereng. Data dari hasil pengujian sondir harus dikonversikan dahulu ke bentuk nilai kuat geser "undrained" $\left(S_{u}\right)$ sehingga sesuai dengan keperluan analisis lereng (Abdul Hakam, 2010).

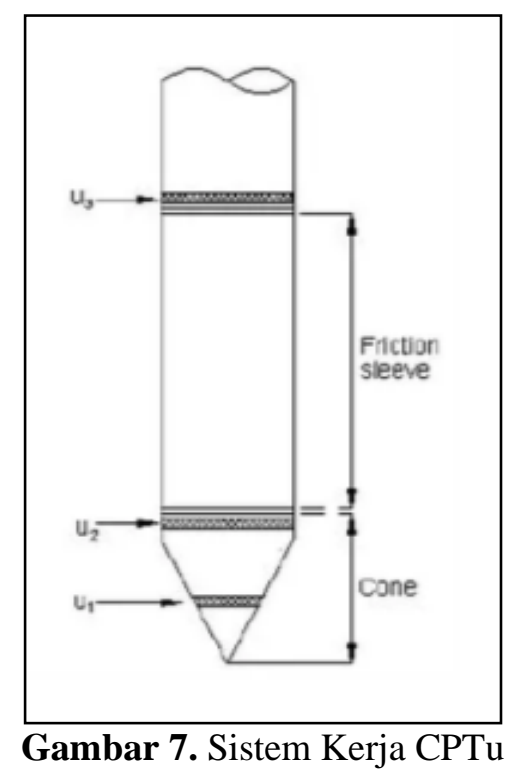

Uji Sondir atau dikenal dengan CPT itu dapat memperoleh nilai perlawanan konus dan friction ratio tanah secara terus menerus di sepanjang kedalaman tanah. Dalam pengembangannya ada uji $\mathrm{CPTu}$ yang mana selain memperoleh nilai perlawananan konus dan friction ratio tanah, uji ini memperoleh tegangan air pori tanah. Perkembangan uji sondir yang disertai pengukuran tekanan air pori ini kemudian dikenal dengan nama CPTu atau Piezocone Penetrometer Test. CPTu dapat mengukur tekanan air pori dari pengukuran $\mathrm{u}_{1}, \mathrm{u}_{2}$ dan $\mathrm{u}_{3}$ pada interval kedalaman tiap pengukuran $q_{t}$ (hambatan konus) dan $f_{s}$ (hambatan lekat).

Analisa tingkat konsistensi tanah lempung dari sondir dapat menggunakan Tabel Terzaghi dan Peck (1948).

Tabel 2. Tingkat Konsistensi Tanah Lempung terhadap Tahanan Konus Sondir (Terzaghi dan Peck, 1948)

\begin{tabular}{cc}
\hline Kosistensi & $\mathbf{q}_{\mathbf{t}}\left(\mathbf{k g} / \mathbf{c m}^{\mathbf{2}}\right)$ \\
\hline Tanah Sangat Lunak & $<5$ \\
Tanah Lunak & $5-10$ \\
Tanah Agak Lunak & $10-35$ \\
Tanah Sedang/Kaku & $30-60$ \\
Tanah Agak Keras & $60-120$ \\
Tanah Keras & $>120$ \\
\hline
\end{tabular}




\section{LOKASI PENELITIAN, INSTRUMENTASI AKUISISI DATA GPR, ALUR KERJA PENELITIAN DAN INTERPRETASI DATA GPR}

Pada penelitian ini berada di lokasi Settling Pond milik PT.Kaltim Prima Coal, Kecamatan Bengalon, Kabupaten Kutai Timur, Provinsi Kalimantan Timur. Hasil rona awal lokasi tersebut adalah sebagian besar rawa-rawa dan sebagian lagi berupa tanah bekas rawa-rawa. Litologi daerah penelitian tersusun atas tanah lunak yaitu gambut, lanau lempungan dan pasir lempungan.

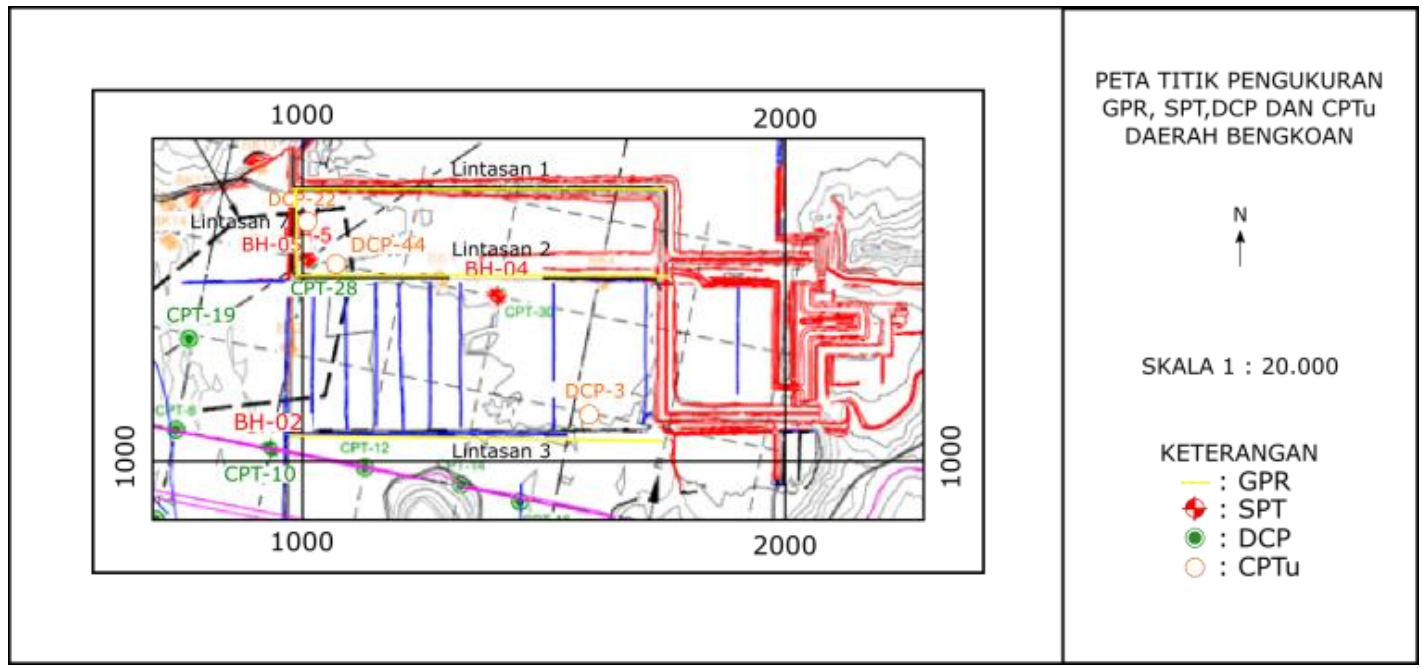

Gambar 8. Peta Lintasan GPR dan Titik Pengukuran CPT

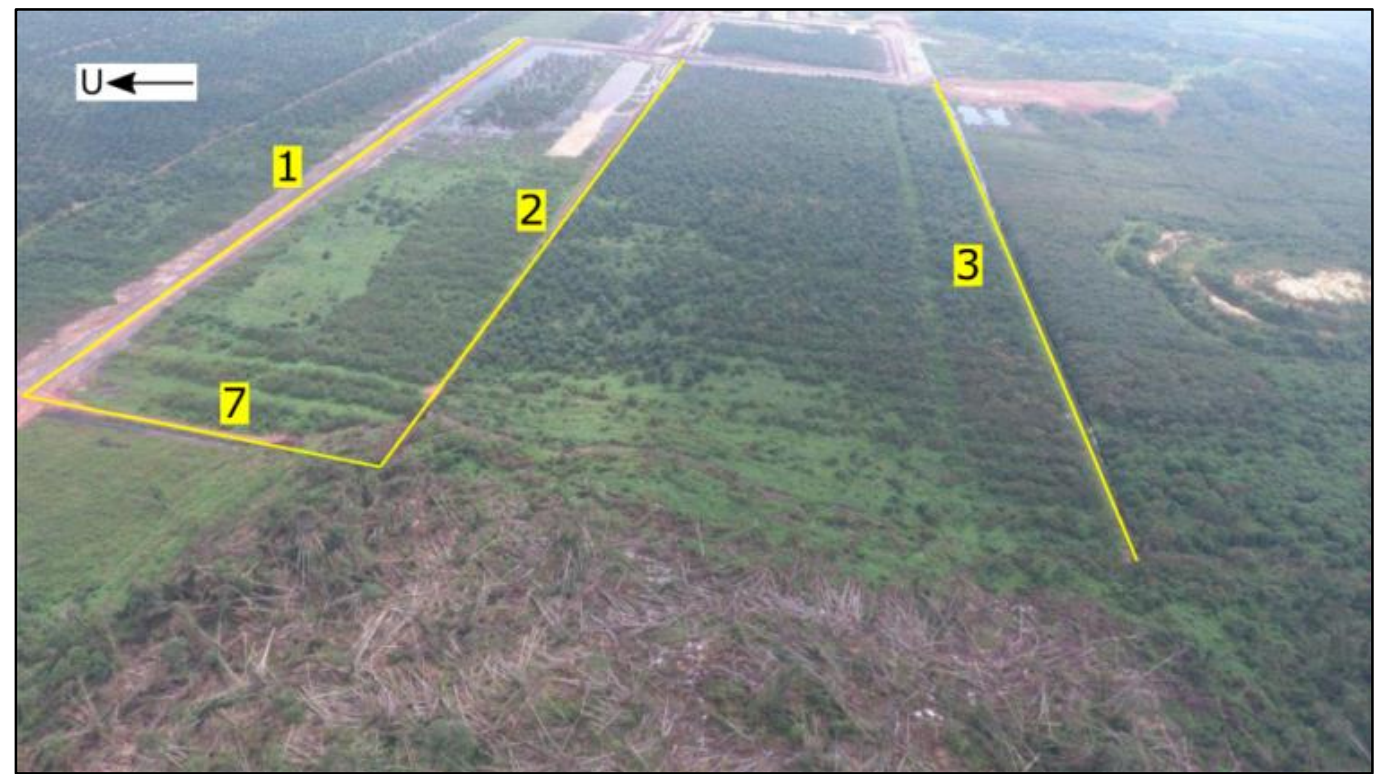

Gambar 9. Lokasi Penelitian GPR

Sebagai perlengkapan akuisisi data Ground Penetrating Radar, tim geoteknik KPC menggunakan alat GPR IDS tipe RIS-ONE Antenna TR $40 \mathrm{MHz}$ yang terdiri atas rangkaian sensor (sebelah kiri) dan control unit DAD-1CH (sebelah kanan). Pada spesifikasi tipe antenna yang dipakai sebagai transmitter adalah Unshielded Dipole dengan frekuensi $40 \mathrm{MHz}$ dengan jarak antara transmitter dengan receiver yaitu 1,2 meter dengan berat $18 \mathrm{~kg}$.

Data Ground Penetrating Radar yang digunakan dalam penelitian ini berupa raw data dengan format dat. Terdapat 4 lintasan data Ground Penetrating Radar yang dapat diolah menggunakan 
software ReflexW v4.5. Langkah pengolahan dan analisa data pada penelitian dijelaskan sebagai berikut:

1. PRE-PROCESSING

Tahap pre-processing terdiri dari memuat data yang diperlukan dalam korelasi data pada area tersebut. Data tersebut diantaranya :

a. Raw data Ground Penetrating Radar yaitu Lintasan 1, Lintasan 2, Lintasan 3 dan Lintasan 7

b. Data Sondir, yaitu CPT 10, CPT 19 dan CPT 28.

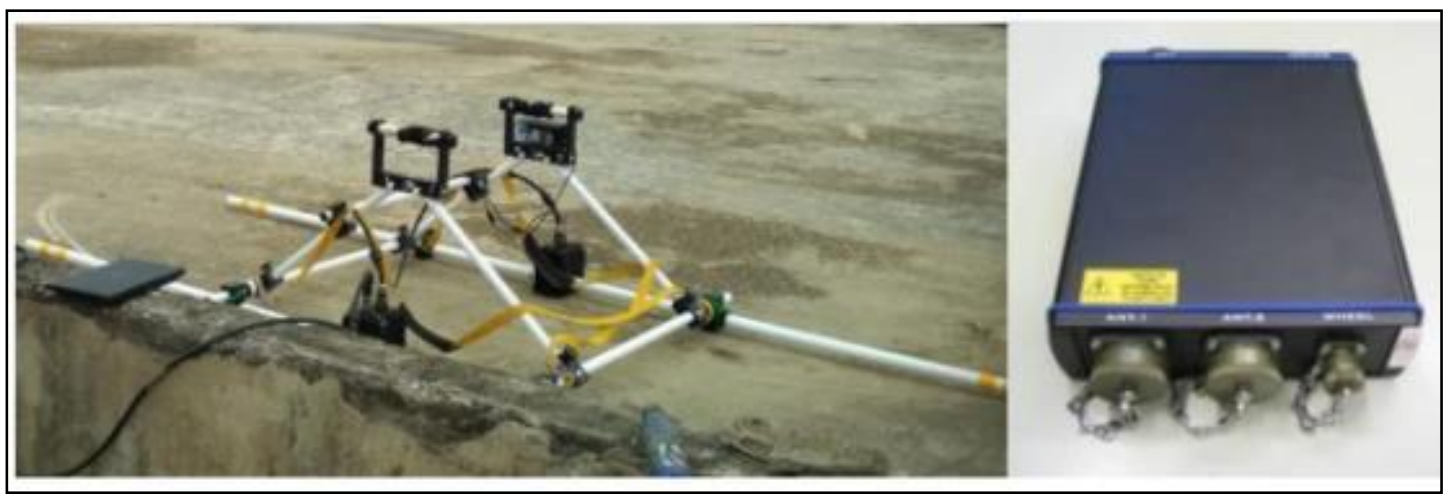

Gambar 10. Instrumen Akusisi Data FS

\section{PROCESSING}

Setiap data $G P R$ yang diperoleh dari hasil pengukuran lapangan pasti terdapat noise yang dapat menganggu kuat sinyal gelombang elektromagnetik. Noise terjadi akibat adanya gangguan gelombang elektromagnetik dari dalam maupun dari luar alat akuisisi. Noise dari alat terjadi akibat saturasi gelombang langsung dari transmitter ke receiver secara elektronik. Jika noise dari luar alat seperti alat akuisisi GPR dekat dengan tower listrik, membawa atau menggunakan alat komunikasi seperti HP ataupun HT atau benda elektronik yang lainnya, Noise tersebut akan membuat data menjadi tidak merepresentasikan keadaan yang sebenarnya di bawah permukaan. Untuk menghilangkan noise atau untuk mengurangi noise tersebut maka dilakukan pengolahan data.

Pengolaan data GPR pada penelitian menggunakan software ReflexW v4.5. Langkah-langkah yang dilakukan (Lihat Gambar 11) dalam proses pengolahan ini bertujuan untuk meningkatkan rasio antara sinyal dan noise (signal to noise ratio) dan mendapatkan visualisasi target yang representative.

\section{POST-PROCESSING}

Pada tahap Post-Processing terdiri dari menganalisa data Ground Penetrating Radar untuk menghitung nilai konstanta dielektrik pada kedalaman tiap lintasan dengan korelasi data bor SPT, DCP dan CPT sehingga dapat mengetahui hubungan parameter fisisnya. Langkahlangkahnya diantaranya :

a. Penentuan batas kedalaman

b. Perhitungan kecepatan mewakili tiap ketebalan lapisan menggunakan Metode Kruk

c. Perhitungan konstanta dielektrik menggunakan rumus kecepatan gelombang elektromagnetik (Reynold, 2011).

Setelah memenuhi langkah diatas, maka selanjutnya adalah intrepretasi data akuisisi $G P R$.

\section{INTERPRETASI}

Langkah-langkah yang dilakukan pada tahap Intrepretasi adalah korelasi data GPR dan CPT. Data $G P R$ yang sudah diketahui nilai konstanta dielektrik tiap lapisan dapat dikorelasikan dengan nilai pengukuran CPT yaitu berupa nilai qt (hambatan konus) dan $f s$ (hambatan lekat). 


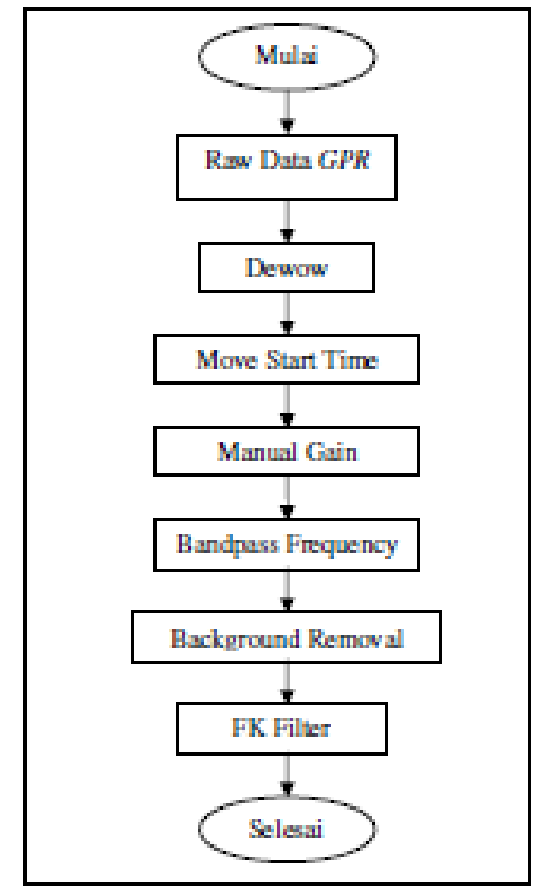

Gambar 11. Diagram Alir Processing

\section{HASIL DAN PEMBAHASAN}

\section{D.1. Interpretasi Data GPR}

\section{D.1.1. Lintasan 1}

Pada penampang Lintasan 1 terdiri atas 4 lapisan dengan kedalaman maksimal mencapai 11,6 meter. Lapisan 1 dengan kedalaman 0 sampai 1,8 meter memiliki konstanta dielektrik 48,18 yang diinterpretasikan lempung pada tanah timbunan dengan kandungan air yang relatif rendah. Pada lapisan 2 dengan kedalaman 1,8 sampai 5 meter memiliki konstanta dielektrik 51,72 diinterpretasikan sebagai lempung organiK dengan kandungan air relatif rendah. Pada lapisan 3 dengan kedalaman 5 sampai 9 meter memiliki konstanta dielektrik 52,36 diinterpretasikan sebagai lempung organik, terdapat sisipan lempung yang lebih kuat lagi pada kedalaman 7,4 sampai 7,9 meter dengan konstanta dielektrik 21,94, kandungan air relatif sangat rendah. Pada lapisan 4 dengan kedalaman 9 sampai 11,6 meter memiliki konstanta dielektrik 50,83 diinterpretasikan sebagai lempung dengan kandungan air relatif rendah.

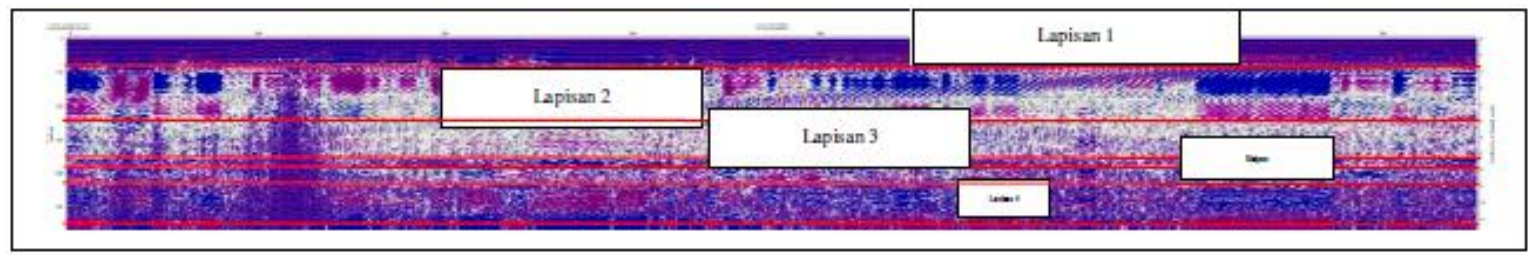

Gambar 12. Penampang GPR Lintasan 1

\section{D.1.2. Lintasan 2}

Pada penampang Lintasan 2 terdapat 5 lapisan dengan kedalaman maksimum 11,6 meter. Akan tetapi, pada lapisan terakhir tidak dapat dihitung karena tidak diketahui tebalnya pada penampang (masih menerus). Lapisan 1 dengan kedalaman 0 sampai 1,5 meter memiliki konstanta dielektrik 53,73 yang diinterpretasikan lempung sebagai tanah timbunan. Pada lapisan 2 kedalaman 1,5 sampai 4 meter memiliki konstanta dielektrik 58,9 yang diinterpretasikan gambut. Pada lapisan 3 
kedalaman 4 sampai 8 meter memiliki konstanta dielektrik 61 yang diinterpretasikan gambut yang relatif lebih lunak. Terdapat adanya sisipan lempung yang kandungan air relatif sangat rendah pada kedalaman 6,7 sampai 7,3 meter dengan konstanta dielektrik 11. Pada lapisan 4 pada kedalaman 8 sampai 9,8 meter memiliki konstanta dielektrik 56 diinterpretasikan gambut kandungan airnya relatif rendah.

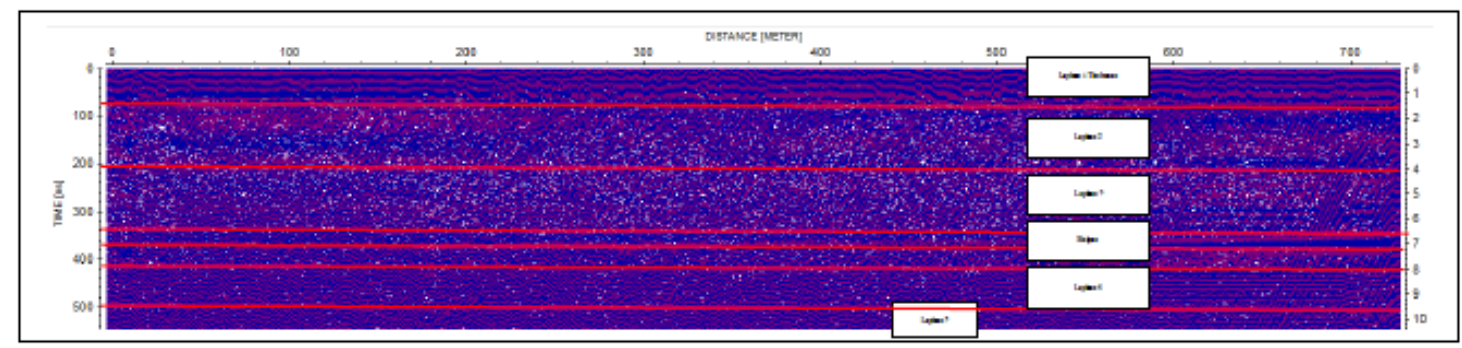

Gambar 13. Penampang GPR Lintasan 2

\section{D.1.3. Lintasan 3}

Pada penampang Lintasan 3 terdapat 4 lapisan, untuk lapisan 1 dengan kedalaman 0 sampai 1,4 meter memiliki konstanta dielektrik 52,65 yang diinterpretasikan lempung yang kandungan airnya relatif rendah, sebagai tanah timbunan. Pada lapisan 2 kedalaman 1,4 sampai 5 meter memiliki konstanta dielektrik 60,64 yang diinterpretasikan gambut yang kandungan airnya relatif banyak. Pada lapisan 3 kedalaman 5 sampai 8 meter memiliki konstanta dielektrik 59,92 yaitu lapisan gambut yang kandungan air relatif sedang dan terdapat adanya sisipan lempung yang kandungan airnya relatif sangat rendah pada kedalaman 7,04 sampai 7,32 meter dengan konstanta dielektrik 11,14. Pada lapisan 4 dengan kedalaman 8 sampai 10,6 meter memiliki konstanta dielektrik 59,17 diinterpretasikan gambut yang kandungan airnya relatif rendah.

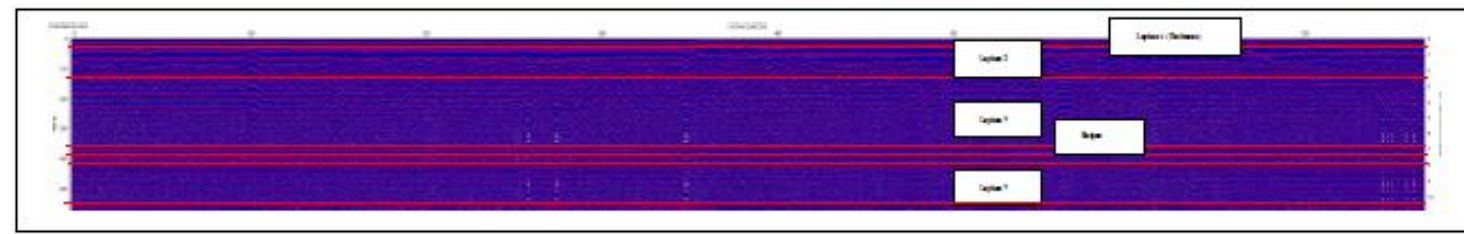

Gambar 14. Penampang GPR Lintasan 3

\section{D.1.4. Lintasan 7}

Pada penampang Lintasan 7 terdapat 3 lapisan dengan kedalaman maksimum 8.9 meter. Lapisan 1 dengan kedalaman 0 sampai 1,3 memiliki nilai konstanta dielektrik 51,38 sebagai lempung d sebagai tanah timbunan. Pada lapisan 2 kedalaman 1,3 sampai 4,4 meter memiliki konstanta dielektrik 60 yang diinterpretasikan lapisan gambut dengan kandungan air yang relatif tinggi. Pada lapisan 3 kedalaman 4,4 sampai 8,2 meter memiliki konstanta dielektrik 60,8 yang diinterpretasikan gambut kandungan air yang relatif tinggi. Sisipan pada kedalaman 8,2 sampai 8,9 diinterpretasi sebagai lempung dengan kandungan air yang relatif rendah dengan konstanta dielektrik 35,9.

\section{D.2. Analisa Akuisisi Data Interpretasi GPR dengan Data $C P T$}

\section{D.2.1. Akuisisi Data Interpretasi GPR Lintasan 2 - CPT 28}

Pada Gambar 16 memberikan informasi tentang korelasi data CPT 28 dengan Konstanta Dielektrik Lintasan 2 dari GPR dengan mengabaikan tanah timbunan. Pada Grafik CPT memperoleh nilai $q t$ (hambatan ujung) dan $f s$ (gesekan selimut). Pada lintasan 2 terdapat adanya perbedaan permitivitas pada tiap lapisan. Lapisan 1 dengan kedalaman 0 sampai 2,5 meter memiliki nilai konstanta dielektrik 58,9 diinterpretasikan gambut dengan nilai $q_{t}$ median senilai 
0,19 MPa dan $f s$ median $11 \mathrm{kPa}$. Pada lapisan 2 dengan kedalaman 2,5 sampai 6,7 meter memiliki nilai konstanta dielektrik 61,08 diinterpretasikan gambut dengan $q t$ median $0,18 \mathrm{MPa}$ dan $f s$ median 1,8 $\mathrm{kPa}$ dengan ada sisipan lempung yang lebih padat pada kedalaman 5,2 sampai 5,8 meter dengan nilai konstanta dielektrik senilai 31 dengan nilai $q t$ median 0,202 MPa. Pada lapisan 3 dengan kedalaman 6,7 sampai 8,3 meter memiliki nilai konstanta dielektrik 56,09 diinterpretasikan gambut yang cenderung lebih padat dengan $q t$ median $0,22 \mathrm{MPa}$ dan $f_{s}$ median $1,13 \mathrm{kPa}$.

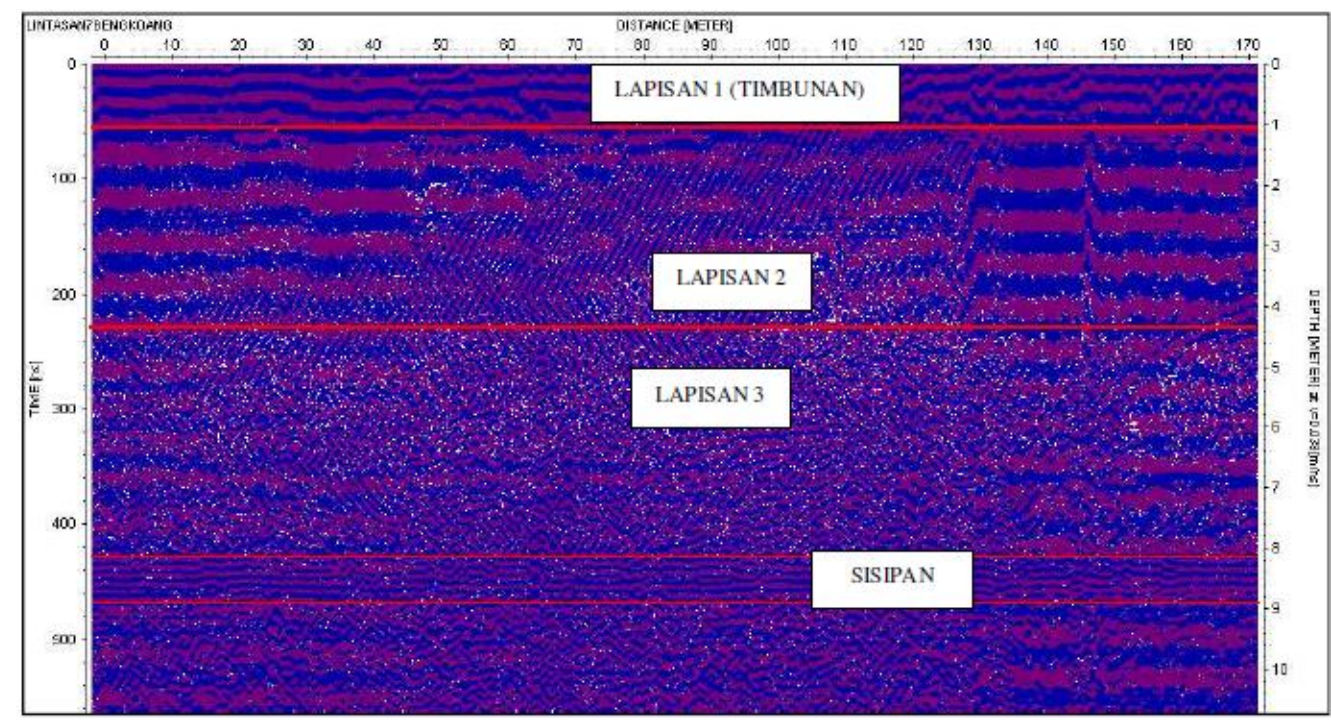

Gambar 15. Penampang GPR Lintasan 7

\section{D.2.2. Akuisisi Data Interpretasi GPR Lintasan 3 - CPT 10}

Pada Gambar 17 memberikan informasi tentang korelasi data CPT 10 dengan Konstanta Dielektrik Lintasan 3. Pada Grafik CPT memperoleh nilai $q t$ (hambatan ujung) dan $f s$ (gesekan selimut). Pada lintasan 3 terdapat adanya perbedaan permitivitas pada tiap lapisan. Lapisan 1 dengan kedalaman 0 sampai 3,6 meter memiliki nilai konstanta dielektrik 60,64 diinterpretasikan gambut dengan nilai $q t$ median senilai $0,13 \mathrm{MPa}$ dan $f s$ median $6,57 \mathrm{kPa}$. Pada lapisan 2 dengan kedalaman 3,6 sampai 6,6 meter memiliki nilai konstanta dielektrik 59,92 diinterpretasikan gambut dengan $q t$ median $0,18 \mathrm{MPa}$ dan $f s 10,52 \mathrm{kPa}$ dengan ada sisipan lempung yang lebih padat pada kedalaman 7,04 sampai 7,32 meter dengan nilai konstanta dielektrik senilai 11 dengan qt 0,5 MPa. Pada lapisan 3 dengan kedalaman 6,6 sampai 9,2 meter memiliki nilai konstanta dielektrik 59,17 diinterpretasikan gambut yang cenderung lebih padat dengan $q t$ median $0,16 \mathrm{MPa}$ dan $f s$ median $3,55 \mathrm{kPa}$.

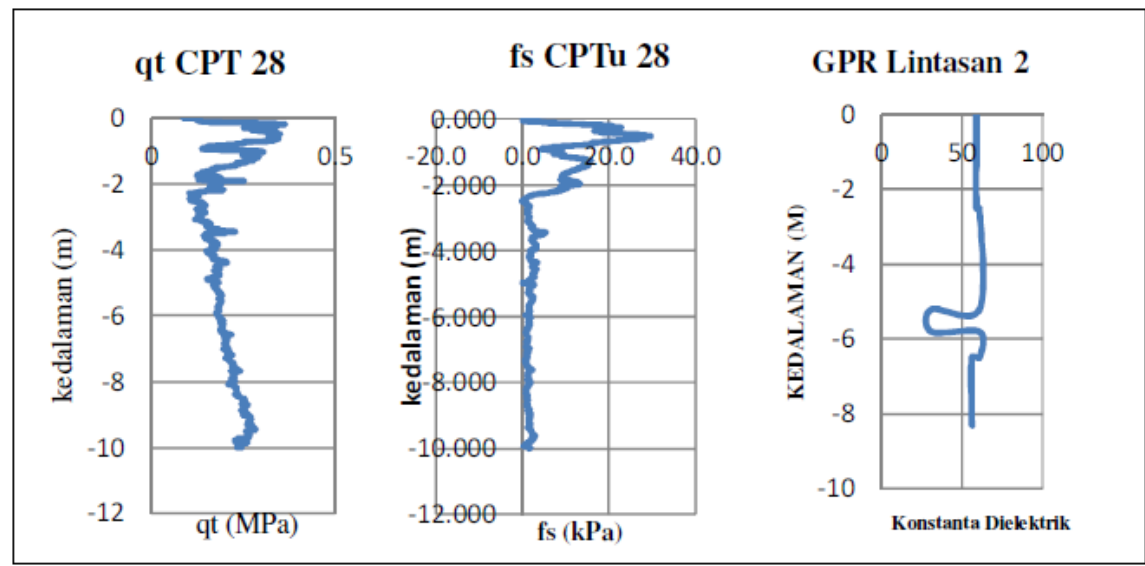

Gambar 16. Grafik CPT 28 vs Konstanta Dielektrik GPR Lintasan 2 


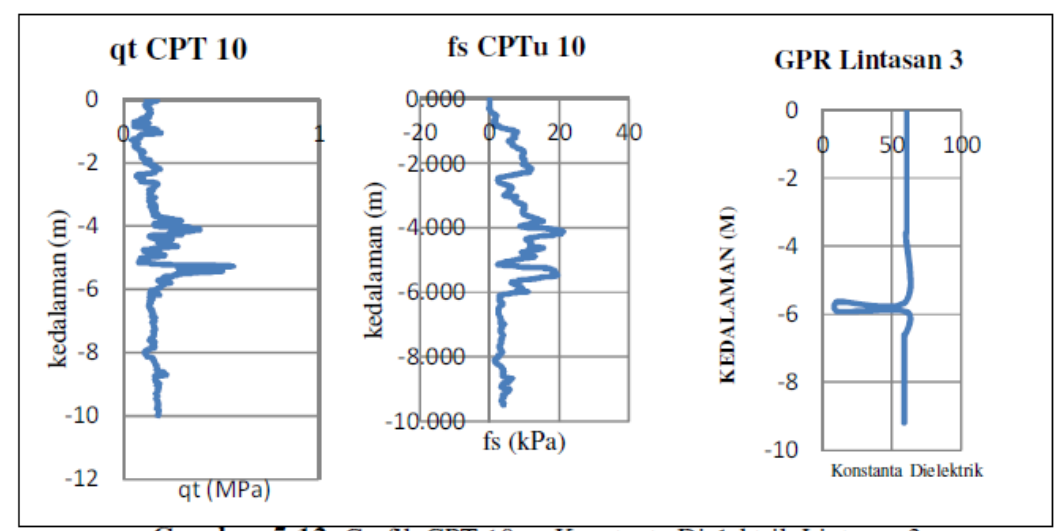

Gambar 17. Grafik CPT 10 vs Konstanta Dielektrik GPR Lintasan 3

\section{D.2.3 Akuisisi Data Interpretasi GPR Lintasan 7 - CPT 19}

Pada Gambar 18 memberikan informasi tentang korelasi data CPT 19 dengan Konstanta Dielektrik Lintasan 7 GPR. Pada Grafik CPT memperoleh nilai qt (hambatan ujung) dan $f s$ (gesekan selimut). Pada lintasan 2 terdapat adanya perbedaan permitivitas pada tiap lapisan. Lapisan 1 dengan kedalaman 0 sampai 3,1 meter memiliki nilai konstanta dielektrik 61,85 diinterpretasikan gambut dengan nilai $q t$ median $0,168 \mathrm{MPa}$ dan $f s$ median 9,6 kPa. Pada lapisan 2 dengan kedalaman 3,1 sampai 6,9 meter memiliki nilai konstanta dielektrik 60,8 diinterpretasikan gambut yang relatif lunak dengan nilai $q t$ median $0,15 \mathrm{MPa}$ dan $f s$ median $6,26 \mathrm{kPa}$.

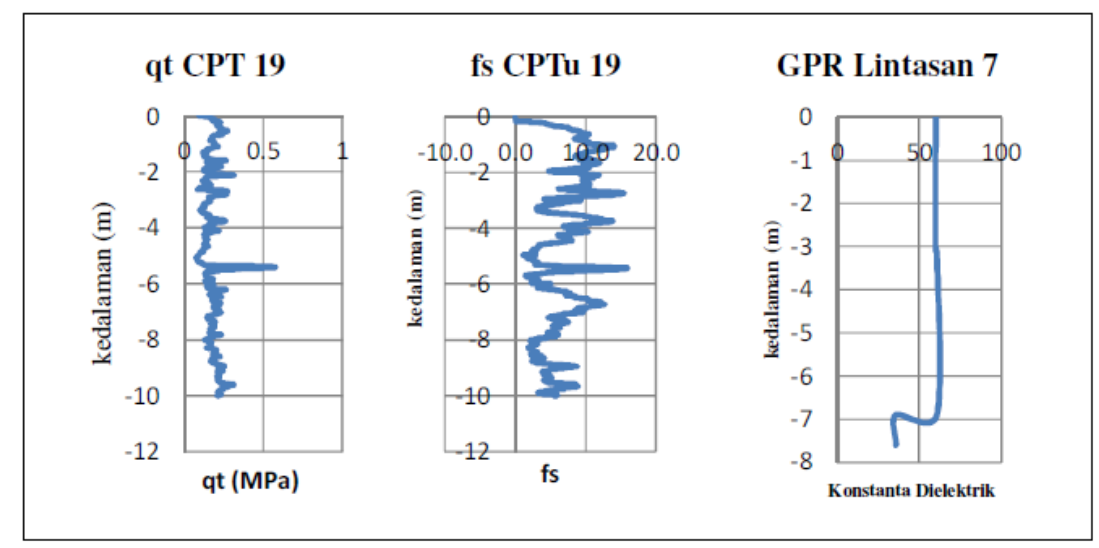

Gambar 18. Grafik CPT 19 vs Konstanta Dielektrik GPR Lintasan 7

\section{D.2.4 Perhitungan $q_{t}$ tiap lintasan GPR}

Hubungan nilai $q_{t}$ (hambatan konus) dengan Konstanta Dielektrik memperoleh rumus empiris yaitu $\boldsymbol{y}=-\mathbf{0 . 0 1 2 6} \boldsymbol{x}+\mathbf{0 . 9 2 4}$ dengan nilai y adalah $q t$ atau hambatan konus dari CPT dan $\mathrm{x}$ adalah nilai Konstanta Dielektrik yang diperoleh dari lintasan Ground Penetrating Radar. Sehingga diperoleh persebaran nilai $q t$ pada lintasan 2, 3 dan 7. Pada Gambar 19 menjelaskan nilai $q t$ ratarata dari lapisan-lapisan lintasan GPR dengan mengaibaikan timbunan dan sisipan pada lapisan tersebut sampai kedalaman penetrasi $G P R$ yaitu pada kedalaman batas bawah timbunan dengan kedalaman batas akhir lintasan GPR yang diperoleh.

Pada lintasan 2 memiliki nilai $q t$ rata-rata sebesar $0.18 \mathrm{MPa}$. Untuk lintasan 3 memiliki nilai $q t$ rata-rata sebesar $0.17 \mathrm{MPa}$. Sedangkan pada lintasan 7 memiliki nilai $q t$ rata-rata sebesar 0.157 MPa. Lintasan 1 memiliki nilai $q t$ rata-rata sebesar $0.26 \mathrm{MPa}$. Nilai $q t$ rata-rata terbesar yaitu pada lapisan 1. Hal ini menyatakan bahwa pada daerah lintasan 1 memiliki lapisan dengan nilai $q t$ yang relatif besar diantara daerah lintasan yang lain. $0.26 \mathrm{MPa}$ dapat diartikan yaitu $260 \mathrm{kPa}$ atau 2,651 $\mathrm{kg} / \mathrm{cm}^{2}$. Lintasan 1 dibawah lapisan timbunan memiliki berat yang lebih besar dibandingkan dengan lintasan yang lain. Pada lapisan lintasan 1 dengan kedalaman 2 meter sampai 10 meter memiliki penambahan qt yang lebih besar diantara lintasan yang lainnya. Hal ini dikarenakan 
adanya distribusi tekanan dari lapisan imbunan sehingga meningkatkan berat lapisan yang dibawah timbunan.

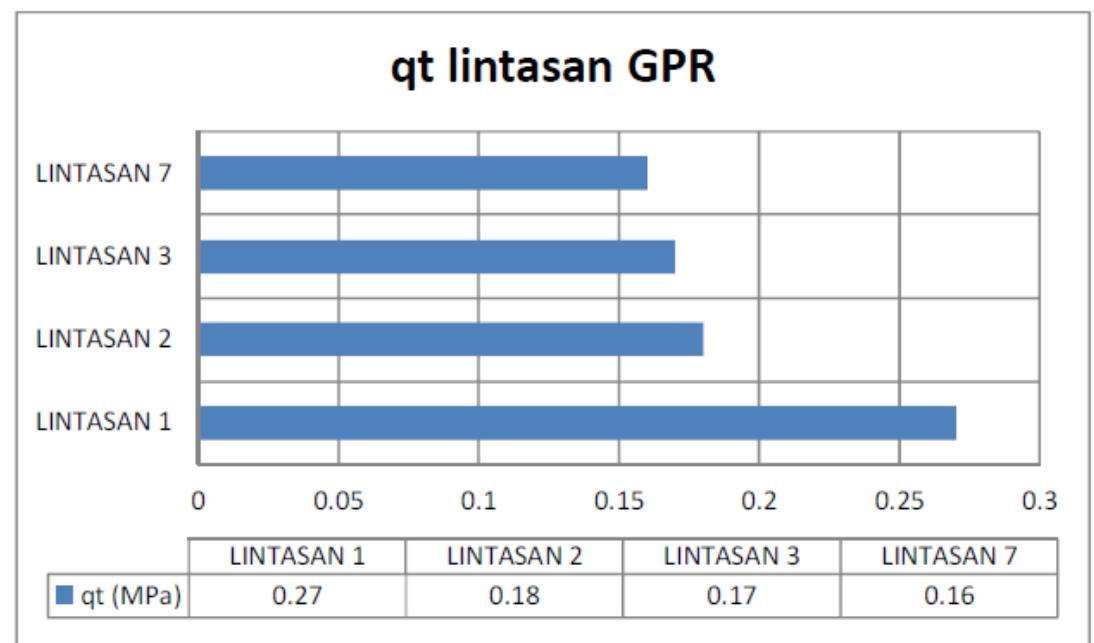

Gambar 19. Nilai $q t$ rata-rata tiap lintasan $G P R$

\section{E. KESIMPULAN}

Berdasarkan hasil analisis data GPR dengan data CPT, dapat disimpulkan:

- Pada penampang lintasan 1 terdapat empat lapisan, penampang lintasan 2 terdapat empat lapisan, penampang lintasan 3 terdapat empat lapisan, penampang Lintasan 7 terdapat tiga lapisan. Konsistensi lapisan 1 adalah timbunan, lapisan 2 adalah gambut tersaturasi penuh, lapisan 3 adalah lempung lunak dan lapisan 4 adalah gambut terpadatkan.

- Pada korelasi nilai CPT dengan interpretasi GPR diperoleh bahwa nilai Konstanta Dielektrik pada rentang 56,09 sampai 61,08 memiliki nilai $q t$ dengan rentang 0,12 MPa sampai $0,21 \mathrm{MPa}$ setara dengan tanah lempung agak keras/lempung organik/gambut sampai lempung keras

- Hubungan nilai hambatan konus CPT $\left(q_{t}\right)$ dengan konstanta dielektrik $\left(\varepsilon_{r}\right)$ dapat dituliskan sebagai persamaan empiris dibawah ini:

$\boldsymbol{q}_{\boldsymbol{t}}=-0.0126 \cdot \varepsilon_{r}+\mathbf{0 . 9 2 4}$

- Metode GPR dapat digunakan untuk menunjang detail interpretasi pengeboran geologi dan interpretasi seam batubara multi-layering pada saat penambangan. Serta sebagai metode alternatif jika metode pengeboran geologi terlalu berbahaya dilakukan karena lereng yang diinvestigasi berada pada kondisi kritis atau area rawa/tanah ekstrim lunak yang tidak bisa dilalui mobilisasi rig drilling.

\section{DAFTAR PUSTAKA}

Arif, Irwandi. 2016. Geoteknik Tambang:Mewujudkan Produksi Tambang yang Berkelanjutan dengan Menjaga Kestabilan Lereng. Jakarta:Gramedia.

David, J. L., and A. P. Annan. 1989. Ground Penetrating Radar for High-Resolution Mapping of Soil and Rock Stratigraphy. Geophysical Prospecting.

Hakam, Abdul. 2010. Stabilitas Lereng dan Dinding Penahan Tanah. Padang:Ferila.

ISSMFE Technicl Commite on Penetration Testing. (1998). Standard Penetration Test (SPT): International Refrence Test Procedure, Thornburn, S. (chairman) Orlando:. Proc. The First Int. Symp on Penetration Testing/ISOPT-1. 